\title{
Open Stacks and Library Performance
}

\begin{abstract}
Although the utility of open stack systems has been widely debated, little empirical research relevant to the controversy is available. Using circulation, book availability, and search and library-use statistics, major elements of the direct access debate are tested in a six-year study of a library that has recently undergone the transition from closed to open stacks. Direct shelf access, it was found, contributed to an increase in library use and a decrease in circulation. Contrary to expectations, book availability performance also improved significantly during the study period.
\end{abstract}

\section{D} practice in American academic libraries today and enjoys considerable support among faculty members, students, and librarians. Despite their popularity, open stack systems have not been incontrovertibly proven more effective than the closed or semiclosed alternatives as user access mechanisms. Nor is the ongoing debate likely to resolve the issue, since the discussion is largely impressionistic and speculative.

Considerable research on patron behavior is available. However, the few quantitative studies relevant to the controversy focus on user behavior in the stacks rather than the broader issue of open access per se. Inferences about the validity of open stack systems have been drawn from measures of patron shelf failure and browsing effectiveness in these reports.

The effectiveness of direct access could be established from statistical case studies comparing library performance before and after the stacks were opened. However, no such empirical impact studies were identified in a search of Library Literature.

The opening of the main library stacks at West Virginia University in February 1976 provided an opportunity for such a longitudinal analysis. Complete circulation, building use, and search statistics had been kept during the three-year periods preceding and

Harold B. Shill is chief circulation librarian and assistant professor of library science, West Virginia University, Morgantown. following the opening of the stacks. Moreover, book availability studies had been conducted during peak use periods before and after the decision. Access to this body of data made possible a study of library performance, using several dependent variables, under changing conditions of shelf access.

\section{THE IsSUE}

The debate over open stacks is multifaceted, encompassing such diverse issues as the effectiveness of browsing, the value of close classification, storage policy, the educational role of the library, and collection security. It also reflects various conceptions of the patron/collection interface articulated by librarians during the past 150 years.

Closed stack libraries were predominant in Europe until the post-World War II period, with books shelved in accession order or by size. This arrangement conserved shelf space and made detailed subject classification unnecessary.

The demand for general access to the shelves originated in the mid-1800s, largely as an outgrowth of the public library movement. The concept was consonant with democratic theory and was adopted by many college libraries and some university libraries, though most of the large research collections in this country remained closed or semiclosed until well into the twentieth century. ${ }^{1}$

In recent decades, however, most academic library buildings have been designed to support open stack operations, 
and many libraries have liberalized access despite architectural shortcomings. In the latter case, the decision has often been made without full advance appreciation of its consequences. ${ }^{2}$

Many theoretical and practical arguments have been advanced in favor of open access. In a survey conducted in the 1950 s, Hicks found widespread expectations that an open stack system would eliminate unnecessary barriers between readers and the collection, increase circulation, permit staff reductions, and elicit patron support. ${ }^{3}$ In his chapter "The Educational Function of the Library," Lyle concluded that "open stacks makes [sic] possible the intelligent use of library resources," assuming good library management and faculty promotion of systematic library research. ${ }^{4}$ Celoria, an archaeologist, maintained that researchers can remain abreast of advances in sister disciplines by mastering the "higher browsing."5 Other advocates of direct access insist that it enhances human dignity and produces a variety of other social benefits.

An equally impressive set of arguments has been arrayed against the open stack concept. The most familiar of these are custodial in origin-increases in theft and mutilation, reduced book availability due to misshelving, greater costs for book replacements and staff, inadequacies of building design, and inefficient use of shelf space. ${ }^{6}$

Criticism has also been advanced at a loftier theoretical level. Ratcliffe and others, expanding upon the conventional argument that students cannot function well in an open stack system, maintain that open access encourages users to bypass the card catalog and other bibliographic tools. The consequence of this tendency, they continue, is to impair the library's performance of its educational role by fostering a decline in bibliographic research skills and systematic library use. ${ }^{7}$

A second argument, applicable particularly to large research libraries, is that the utility of browsing in a classified shelf arrangement varies in a roughly inverse manner with collection size. Drawing upon search theory, Morse inferred that browsing has its own law of diminishing returns:

The trouble comes when the collection becomes too large for all of it to be easily accessible to all, or when even one class becomes so large that it cannot be scanned efficiently in a fraction of an hour. ${ }^{8}$

Ratcliffe contended that a classified subject arrangement is helpful to the browser only in a small or medium-size library. He identified the University of Manchester, with holdings exceeding one million items in 1969 , as a library that has passed this size threshold and is gradually restricting patron access to its collection. ${ }^{9}$ This argument is also supported by Hyman's finding that most librarians consider shelf classification more valuable as a locational device than for subject searches. ${ }^{10}$

Common to all these contributions, both pro and con, is a virtual absence of empirical data to support the authors' contentions. Factual data relevant to the controversy must be sought elsewhere.

\section{Previous Research Results}

Although the open access question is addressed indirectly in many user behavior studies, Cooper's 1957 article remains the only analysis of the impact upon library performance of a transition to open stacks. While generally supportive of the University of Washington's decision, her report does identify several dysfunctional consequences of the decision, including increases in misshelved books, searches, and noise in the stacks and initial dissatisfaction among undergraduates accustomed to book delivery service. Improved patron service and greater long-term user satisfaction, a result attributed to the opportunity to browse, are cited as benefits of the decision. ${ }^{11}$

Several interrelated factors account for book availability performance. Buckland reported that a variable loan policy and demand-based selection of duplicate copies produced a sharp increase in book availability at the University of Lancaster. ${ }^{12}$ Saracevic, Shaw, and Kantor found that circulation performance at Case Western Reserve University improved from 77 percent to 87 percent after the loan period was shortened. ${ }^{13}$

The effectiveness of library security measures, whether manual or electronic, is an important determinant of a library's ability to deliver books when requested. Confirming a principal finding of the Case Western 
Reserve study, Smith and Granade discovered that 14 percent of the titles not located by patrons in the University of Tennessee's Undergraduate Library were in their proper shelf locations. ${ }^{14}$ This last finding is particularly germane to the open-access debate, since it demonstrates that undergraduates encounter some difficulty with classified shelf arrangements even in medium-size libraries.

Studies of stack use at the Library of Congress, the University of Chicago's Harper Library, and Johns Hopkins University indicate that collection size does not deter browsing in an open-stack research library. Dubester reported that 38 percent of the individuals interviewed in the Library of Congress stacks were browsing rather than searching for specific titles. ${ }^{15}$ Data from Fussler and Simon's Chicago study revealed that 56 percent of the history and physics books removed from their shelf locations had been identified through browsing. ${ }^{16}$ In a follow-up of the Fussler and Simon study, Bowen found that many more books were browsed than checked out, with graduate students comprising the bulk of the open shelf user population. ${ }^{17}$ The Johns Hopkins study conducted in the early $1960 \mathrm{~s}$ confirmed that many items wanted by patrons are initially located through browsing. ${ }^{18}$

The real utility of browsing is questioned in Greene's study of methods used by Georgia Tech faculty members to select books from the library. Greene found that browsing was the most frequently cited method for locating books that were subsequently borrowed. However, browsing was also the least effective method for identifying books that ultimately proved useful. ${ }^{19}$

The potential difficulty of user adaptation from an open stack system to closed stacks is raised by a study conducted at the University of North Carolina. Clay reported that 80 percent of a faculty/graduate student sample interviewed in the stacks felt unable to rely on catalogs and bibliographies as a substitute for browsing. ${ }^{20}$

The studies cited above indicate that users will browse in an open stack library, do locate some books specifically through browsing, and do value direct access to the shelves. Conversely, increased shelf disorder and search failures in a classified collection are identified as counterproductive results of open stack access.

Collection access questions should not, however, be regarded as strictly technical questions that can be resolved in a political vacuum. The University of Toronto Library confronted the latent power of its student and faculty clienteles in 1972, when an attempt to institute a closed-stack policy in a new university library precipitated student demonstrations and critical responses from the Canadian library community. ${ }^{21}$ Faculty members and students, it should be recognized, constitute interest groups able to define broad parameters within which shelf access decisions can be made.

\section{HYPOTHESES}

Certain conceptions about the consequences of open access reappear in both philosophical discussions of the idea and the small body of relevant empirical literature. In particular, one encounters predictions that circulation will increase, while book availability will decline. The anticipated direction of user reaction varies with individual preferences, with advocates of open access predicting increased user satisfaction and opponents forecasting a decline. All of these implicit propositions are susceptible to empirical testing. The decision to open the stacks at West Virginia University's (WVU) main library provided an opportunity to reformulate these ideas as testable propositions and to examine their validity under real-life conditions.

The main library contains approximately 530,000 of the 930,000 physical volumes in the WVU collection. Books in the humanities and social sciences constitute the bulk of the collection, since science materials are concentrated in several branch libraries. The stack area was semi-closed prior to February 1976, with admission restricted to faculty members, graduate students with stack permits, and a few undergraduate honors students. The stacks were opened with minimal publicity, on an "experimental" basis, to permit close monitoring of the decision's impact on library services and to avoid abrupt changes in use patterns. Book delivery service was main- 
tained for those patrons preferring not to retrieve their own books.

Somewhat controlled conditions for analysis existed during the six-year study period, since no branch libraries were opened and no policy changes that might have affected study results were implemented. Enrollment increased from 15,203 in 1973 to 20,964 in 1978 , but allowances for this change have been made in the analysis.

The availability of comparable data for the 1973-78 period permits both the testing of propositions derived from the literature and the investigation of a possible relationship between stack access and library use levels. For purposes of analysis, these propositions are presented in the form of three testable hypotheses:

1. Book circulation will increase if patrons are given greater access to library stack areas.

2. If patrons are given greater access to library stack areas, book availability rates will decline:

a. More books will be unavailable when requested.

b. Book losses through theft will increase.

3. If greater patron access to library stack areas is permitted, use of the library building will increase.

The results of this analysis, it is assumed, will have both theoretical and practical significance. On a theoretical plane, the study should contribute to the development of user behavior theory by explaining patron behavior under changed conditions of collection access. It should also benefit library decision makers by providing a reliable empirical foundation from which decisions re- garding patron access to the stacks can be formulated.

\section{RESULTS AND ANALYSIS}

The hypothesis that circulation levels should increase with open access derives from the assumption that users will borrow more books if they are permitted to browse, rather than having their access limited to specific books identified through bibliographic tools.

Given the substantial growth in enrollment during the study period, circulation would be expected to increase even without a change in stack access. Table 1 , however, reveals a decline in nonreserve circulation throughout the study period. This decline is sharpest in 1976 and 1977, the first two years after the decision to open the stacks.

The decrease is less abrupt when we control for building use loans, a type of transaction that logically occurs with greater frequency in a closed stack system, but a decline of nearly 8,000 loans is found for 1976 even when building use data are excluded from the analysis. (The building loan category includes books returned across the circulation desk that have not been checked out. It excludes books reshelved by patrons, books left on tables or carrels in the stacks and reshelved directly by library personnel, and reserve books.)

Clearly hypothesis 1 must be rejected. This unanticipated decline in circulation would seem most readily explicable as a consequence of reduced book availability or declining building use. Both explanations can be tested with data derived from the study.

The book availability explanation can be

TABLE 1

Nonreserve Circulation before and after Decision to Open LibraRy Stacks

\begin{tabular}{lccc}
\hline \hline Year & $\begin{array}{c}\text { Total } \\
\text { Nonreserve } \\
\text { Circulation }\end{array}$ & $\begin{array}{c}\text { Circulation } \\
\text { excluding } \\
\text { Building } \\
\text { Loans }\end{array}$ \\
\hline 1973 & 194,899 & 45,143 & 149,756 \\
1974 & 192,520 & 46,068 & 146,452 \\
1975 & 185,593 & 43,355 & 142,238 \\
$1976^{*}$ & 167,167 & 32,832 & 134,335 \\
1977 & 149,647 & 16,176 & 133,471 \\
1978 & 146,949 & 14,277 & 132,672 \\
\hline
\end{tabular}

'First year of open stacks. 
tested with search statistics and data gathered from book delivery studies conducted at several intervals in the 1973-78 period. Search statistics, shown in table 2, obviously do not explain the decline in circulation, since a decline in the number of searches was reported in the second and third years of open stacks. The high number of searches conducted in 1976 appears to be the culmination of a long-term trend that was reversed after the stacks were opened.

TABLE 2

SEARChes Conducted, 1973-78

\begin{tabular}{lc}
\hline Year & $\begin{array}{c}\text { Number of } \\
\text { Searches }\end{array}$ \\
\hline 1973 & 3201 \\
1974 & 3775 \\
1975 & 4285 \\
$1976^{*}$ & 4471 \\
1977 & 4039 \\
1978 & 3573 \\
\hline
\end{tabular}

'First year of open stacks.

Since hours of shelf reading remained relatively constant throughout the study period, the reduction in searches in 1977 and 1978 can probably be attributed to students' willingness to "settle" for an alternative book on a particular topic when their first choice was not on the shelf. Thus, while the decrease in searches does not in itself demonstrate an improvement in book availability, it suggests that the collocation of related books on the shelf helped satisfy the needs of many browsing patrons.

A more meaningful measure of book availability in an open stack system can be obtained by comparing book delivery rates longitudinally. Since the main library did continue to provide book delivery service at the circulation desk even after opening the stacks, delivery success data are available for several peak use periods. The results of three statistically comparable studies con- ducted during the 1973-78 period are summarized in table 3.

Since patrons who have searched unsuccessfully for a book in the stacks may also present call slips at the circulation desk, one would expect a deteriorating delivery rate after the stacks were opened even if shelf order remained constant. Instead, table 3 reveals a mild improvement in the percentage of books delivered. This finding indicates even more conclusively than the search statistics in table 2 that the library's book delivery performance was not impaired by the adoption of open access.

Although the question of building use has not been raised previously in the literature, it was assumed that direct access would make the library more attractive to users, thereby contributing to increased use of the facility.

Table 4 confirms that building use did increase dramatically after the opening of the stacks, and particularly in the second year of the new system. This upsurge in building use cannot be attributed to the increase in enrollment during the study period, given a simultaneous decrease in circulation figures. This interpretation of the data is strengthened by the finding of significantly increased library use in 1976, the first year of the open stack system and a year in which enrollment actually declined.

\section{DISCUSSION AND CONCLUSION}

These findings conflict with the conventional assumption that open stack systems contribute to increased circulation and a decline in book availability. Instead, a decline in circulation and a mild increase in book availability were found in the three-year period following the initiation of direct access at West Virginia University. A sharp increase in building use was also observed. Taken together, these findings both chal-

TABLE 3

Delivery Success Rates for Books Requested at Circulation Desk

\begin{tabular}{lccc}
\hline \hline $\begin{array}{l}\text { Date of } \\
\text { Study }\end{array}$ & $\begin{array}{c}\text { Percent Delivered } \\
\text { When Requested }\end{array}$ & $\begin{array}{c}\text { Percent Not Delivered } \\
\text { but Accounted For }\end{array}$ & $\begin{array}{c}\text { Percent Not } \\
\text { Accounted For }\end{array}$ \\
\hline Nov. 1974 & 65.8 & 19.2 & 15.0 \\
April 1977 & 69.2 & 19.6 & 11.2 \\
April 1978 & 70.9 & 16.9 & 12.2 \\
\hline
\end{tabular}

•Includes books in circulation, reserve books, materials at bindery, branch library titles, patron errors in recording call numbers, etc. 
TABLE 4

BUILDING USE BEFORE AND AFTER Adoption of an Open Stack System

\begin{tabular}{lc}
\hline \hline Year & $\begin{array}{c}\text { Persons } \\
\text { Using } \\
\text { Library }\end{array}$ \\
\hline 1973 & 431,285 \\
1974 & 425,708 \\
1975 & 439,607 \\
$1976^{*}$ & 457,373 \\
1977 & 493,068 \\
1978 & 500,178 \\
\hline
\end{tabular}

- First year of open stacks.

lenge prevailing thought about open stacks and suggest some important conclusions about patron behavior in an open access system.

The improvement in book delivery performance indicates that unrestricted patron access does not invariably produce increases in misshelved books and theft if proper precautions are being taken. Close supervision of shelf readers and conscientious checks at the security desk clearly kept the adverse effects of direct shelf access to a minimum.

Increases in shelf reading and stack patrolling are essential in libraries undergoing the transition to open stacks, since many users will misshelve books inadvertently and some do it deliberately, thereby denying access to other potential users. Shifts of personnel from the circulation desk to stack duty may also be required. Since a tight student assistant budget did not permit these adjustments at WVU, meticulous supervision of shelf readers and conscientious security checks were used to minimize the adverse effects of direct shelf access.

The findings of increased building use and decreased circulation suggest that an important change in user search behavior occurs once the stacks have been opened.
Specifically, it appears that after the stacks have been opened users increasingly make relevance decisions at the shelf, rather than borrowing a large number of books with the hope of finding something useful. If this conclusion is correct, improvements in book availability are partially attributable to greater patron selectivity, a tendency that is encouraged by direct access to the collection. If this is the case, and the increase in building use suggests that it is, declines in circulation after the stacks have been opened are probably indicative of improved library service.

The concurrent findings of increased building use and declining circulation also suggest that user adaptation to an open stack system is a generational phenomenon. Library use rises and circulation decreases, it appears, until a plateau is reached when the majority of the student body has been exposed only to a direct-access system.

Initial dissatisfaction with the opening of their exclusive domain may also be expressed initially by faculty members and graduate students, but this discontent can likewise be expected to subside over time.

Several important issues in the shelf access debate are not addressed in this analysis. The study does not, for example, provide any clear evidence whether open stack systems facilitate reader access to paticular books, save money, or promote the educational function of the library. However, this study does indicate that, with proper managerial anticipation of shifting use patterns, the stacks can be opened in a medium-size academic facility with significant benefits for individual patrons and without adversely affecting overall library performance.

\section{REFERENCES}

1. Mathilde V. Rovelstad, "Open Shelves/ Closed Shelves in Research Libraries," College \& Research Libraries 37:457-67 (Sept. 1976).

2. Harold D. Gordon, "Open Stacks: A Second Look," Library Journal 94:1844-45 (May 1, 1969).

3. Warren B. Hicks, "Open or Closed Stacks," College \& Research Libraries 15:309-12 (July 1954).
4. Guy R. Lyle, The Administration of the College Library (4th ed.; New York: Wilson, 1974), p.117.

5. Francis Celoria, "The Archaeology of Serendip," Library Journal 94:1846-48 (May 1, 1969).

6. Hicks, "Open or Closed Stacks," p.311; Gordon, "Open Stacks," p. 1845.

7. F. W. Ratcliffe, "Problems of Open Access in Large Academic Libraries," Libri 18:95-111 
(1968); Hicks, “Open or Closed Stacks," p.311; Gordon, “Open Stacks,” p. 1845.

8. Philip M. Morse, "Search Theory and Browsing," Library Quarterly 40:399 (Oct. 1970).

9. Ratcliffe, "Problems of Open Access," p.109.

10. Richard Joseph Hyman, Access to Library Collections (Metuchen, N.J.: Scarecrow, 1972), p.372.

11. Dorothy B. Cooper, “Open Stacks Open New Doors," Library Journal 82:507-8 (Feb. 15, 1957).

12. Michael K. Buckland, Book Availability and the Library User (New York: Pergamon, 1975), p.94-97, 130.

13. T. Saracevic, W. M. Shaw, Jr., and P. B. Kantor, "Causes and Dynamics of User Frustration in an Academic Library," College d Research Libraries 38:7-18 (Jan. 1977).

14. Rita Hoyt Smith and Warner Granade, "User and Library Failures in an Undergraduate Library," College \& Research Libraries 39:467-73 (Nov. 1978).

15. Henry J. Dubester, "Stack Use of a Research Library," ALA Bulletin 55:891-93 (Nov. 1961).
16. Herman H. Fussler and Julian L. Simon, Patterns in the Use of Books in Large Research Libraries (Chicago: Univ. of Chicago Pr., 1969), p.112. This information is derived from an analysis of Fussler and Simon's table 36 in Robert J. Greene, "The Effectiveness of Browsing," College \& Research Libraries 38:313-16 (July 1977).

17. Alice Bowen, "Non-Recorded Use of Books and Browsing in the Stacks of a Research Library," M.A. thesis, University of Chicago, 1961.

18. Johns Hopkins University, Research Library, Progress Report on an Operations Research and Systems Engineering Study of a University Library (Baltimore: Johns Hopkins Univ., 1963).

19. Greene, "Effectiveness of Browsing," p.316.

20. Sam Clay, "Open Stack Study," Library Journal 94:3378-80 (Oct. 1, 1969).

21. "Toronto Students Win Access to Library Stacks," Library Journal 97:1655-56 (May 1, 1972). 